\title{
Standardization of Drying Methods of different Fruit Types on Storability of Chilli Seed
}

\author{
Chakradhar Patra ${ }^{1}$, Laxmipriya Sahoo ${ }^{2}$, Saroj Kumar Mohanty ${ }^{1}$ \\ and Monalisha Sahoo ${ }^{1}$ \\ ${ }^{1}$ Department of Seed Science \& Technology, College of Agriculture, Orissa University of \\ Agriculture and Technology, Bhubaneswar, Odisha, India \\ ${ }^{2}$ ICAR-Central Institute of Women in Agriculture, Bhubaneswar, India
}

*Corresponding author

\section{A B S T R A C T}

\section{Keywords}

Chilli (Capsicum annuum L.),

Fleshiness index,

Drying methods, Germination percentage

\section{Article Info}

Accepted:

07 September 2019

Available Online:

10 October 2019
The effect of seed drying methods on storability for chilli of different fruit types was studied in Completely Randomized Design (CRD) in four replications with five treatments. The chilli fruits were grouped like slender, moderate and fleshy as per the fleshiness index and are exposed to different drying methods such as sundrying, shade drying, freeze drying, oven drying of fruits and hand extracted seeds on the day of harvest followed by shade drying. Seeds were stored for 10 months and observations were recorded on germination percentage, vigour index in a regular interval of 2 months. Results revealed that fleshy fruit types showed highest germination percentage in shade drying after 2 months of storage (79.14\%) \& reduced gradually whereas lowest found in freeze drying method after 10 months after storage (12.26\%) followed by medium and slender fruit types. After 2 months of storage, shade dried fleshy fruit types of chilli exhibited highest vigour index (943.553) followed by slender \& medium fruit types whereas lowest vigour index found in freeze dried slender fruit types of chilli after 10 months of storage (50.99). Hence both shade drying and hand extracted seeds on the day of harvesting is recommended for drying of chilli seeds.

\section{Introduction}

Chiili (Capsicum annuum L.; $2 \mathrm{~N}=24$ ) is a member of the Solanaceae family. Nearly 30 species were identified under the genus Capsicum. Out of it, only five species C. annuum L., C. baccatum L.; C. chinense
Jacq.; C. frutescens L. and C. pubescens Ruiz $\&$ Pavonand are mostly cultivated and are recognized by International Bureau of Plant Genetic Resources. Among all, C. annuиm L. is the widely cultivated and most explored species. It is an indispensable spice essentially used in every Indian cuisine due to its 
pungency, taste, appealing colour and flavour. Pungency of chilli is due to a crystalline acrid volatile alkaloid called 'capsaicin', present in the placenta of fruit which has diverse prophylactic and therapeutic uses in allopathic and ayurvedic medicine.

Chilli seeds exhibit peculiar behavior in storage requirement. These seeds loose viability quickly after being removed from fruit. Seeds maintain viability for a longer period when they are in fruits than the seeds extracted and stored.

Seeds reported to maintain a higher germination value up to 6 months, when retained in fruits and stored under ambient conditions (RadheSham et al., 1996; Nagaraja et al., 1998b; Sahoo, 2014).

The quality of chilli seeds can be maintained for a long period by adopting different drying methods and also extraction methods.

Chilli, unlike brinjal and tomato, the other members of Solanceae family where seeds are mostly extracted at ripened stage using fermentation method, chilli seed extraction is mostly done after drying of the ripened fruits. However it is reported that chilli seeds express maximum vigour at physiological maturity stage (Sahoo, 2014).

Hence chilli drying is very crucial from seed viability and vigour point of view, as seeds extracted from fruits at physiological maturity is supposed to express maximum vigour.

So for understanding the viability and vigour of chilli seeds, both inside the fruit and extracted at the day of harvest for the entire storage period is a matter of study.

Keeping these propositions in mind, the present experiment was designed to evaluate the drying methods like shade drying, sun- drying, freeze drying, oven drying of chilli with fruits harvested at physiological maturity and hand extraction of seeds on the day of harvest followed by shade drying for identifying suitable drying methods.

\section{Materials and Methods}

\section{Categorization of fruit types in chilli genotypes using fleshiness index}

Chilli fruits were categorized into three types based on their shape characteristics and drying requirements for standardization of drying time, method and storage potential in ambient condition and their effect on seed viability and vigour.

A fleshiness index was developed for this study to categorize different chilli fruit types. The indicators used were the fruit shape (ratio of fruit width and length) and fleshiness (Pericarp thickness). This index is useful in estimating indirectly the fruit cavity volume, which in turn affects the total heat absorption and retention by the fruit, deciding the seed life in terms of viability and vigour during and after drying.

\section{Fleshiness index}

Fleshiness index is a characteristic of both

Fruit Shape (Ratio of fruit width and length)

Fleshiness (Pericarp thickness)

Fleshiness Index $=($ Ratio of fruit width and length) $\times$ Pericarp thickness

$\mathrm{FI}=(\mathrm{W} / \mathrm{L}) \times \mathrm{P}$

Where FI = Fleshiness Index

$\mathrm{W}=$ Width of the fruit at the widest point 
$\mathrm{L}=$ Fruit length excluding the stalk

$\mathrm{P}=$ Pericarp thickness

For this experiment the varieties were categorized in to three groups based on the range of the Fleshiness Index

Slender fruit type (i.e. $\mathrm{FI}=0-0.3$ )

Medium fruit type (i.e. FI = 0.3-0.6)

Fleshy fruit type (i.e. FI > 0.6)

Seed quality attributes in different fruit types with respect to drying and storage condition

For studying the effect of fruit types and drying method on storage potential, 26 treatments were taken including control wherein the genotypes were exposed to 5 drying methods and 5 storage durations.

\begin{tabular}{|l|l|l|l|l|}
\hline M1 : & $\begin{array}{l}\text { Shade } \\
\text { Drying }\end{array}$ & & D1 : & 2 Months \\
\hline M2 : & $\begin{array}{l}\text { Hand } \\
\text { Extracted }\end{array}$ & D2 : & 4 Months \\
\hline M3 : & Sundried & & D3 : & 6 Months \\
\hline M4: & $\begin{array}{l}\text { Freeze } \\
\text { Drying }\end{array}$ & D4 : & 8 Months \\
\hline M5: & Oven Drying & D5 : & $\begin{array}{l}10 \\
\text { Months }\end{array}$ \\
\hline
\end{tabular}

Chilli of different fruit types were exposed to 5 types of drying methods. Harvested fruits were dried under shade, sun, freeze and oven.

Some seeds were extracted manually from the fruits on theday of harvest, washed thoroughly and dried in shade for 2 days and in the sun for 3 days for drying. After drying seeds were stored on air-tight steel container, germination and vigour testing was done at an interval of 2 months.

\section{Seed quality attributes studied}

\section{Germination percentage}

The germination test was carried out using germination papers by the between paper (BP) method (ISTA, 1965) for all the stages. Four such settings for four replications of fruit types of chilli were placed in a germination chamber at $25 \pm 10 \mathrm{C}$ in an upright position. The final count was taken on 14th day and germination (\%)was calculated as percentage of number of normal seedlings divided by no of seeds used for germination test. Separate observations were recorded for different treatments.

\section{Seed Vigour Index (SVI)}

Vigour index was determined for the stages where only germination took place following Abdul-Baki and Anderson, 1973.

Vigour index $(\mathrm{VI})=$ Avg. length of seedlings $(\mathrm{cm}) \times$ Germination $(\%)$

\section{Results and Discussion \\ Standardisation of drying method}

Standardization of drying methods of chilli was done with fruits harvested at physiological maturity. Methods used for drying chilli are shade drying, sun drying, freeze drying and oven drying. Besides above treatments another was hand extraction of seeds on the day of harvest followed by shade drying.

All the 27 studied genotypes of chilli exhibited varying fruit types differing significantly in fruit size, shape, weight and fruit cavity with different pericarp thickness were grouped in to three categories like slender fruit type, medium fruit type and fleshy fruit type using the value of fleshiness 
index and subjected to different treatments as dried fruits are the main source for seed extraction. The dried fruits and seeds of all treatments were subjected to ambient storage condition packed in polythene in sealed container and using destructive sampling.

\section{Germination percentage}

In the category of fleshy fruit type the average germination percentage of chilli seed was found highest in shade drying method (79.139\%) followed by hand extracted seed (77.292) and lowest in freeze drying method (56.569\%) after 2 months of storage. The shade dried fruits had a relative advantage over sun-drying, freeze drying and oven drying with general germination of $22.416 \%$, $36.633 \%, 4.019 \%$ respectively. After 4 months of storage, highest germination percentage was found in shade dried seed (71.028\%) followed by oven dried seed (70.111\%) and hand extracted seed (69.694\%) however germination capacity was similar between oven dried and hand extracted seed and lowest was found in freeze dried seed $(52.278 \%)$. After 4 months of storage, the relative advantage of shade dried fruits over sun-drying, freeze-drying and oven drying were $20.899 \%, 35.866 \%$ and $1.308 \%$. After 6 months of storage, the trend as like as 4 months after storage was observed. But after 8 and 10 months after storage, hand extracted seeds had shown the highest germination percentage than that of other drying methods i.e. $55.250 \%$ and $33.250 \%$ respectively. In the category of medium fleshy type of fruit, the highest germination was found in hand extracted seed $(75.556 \%)$ followed by shade dried seed $(73.986 \%)$ and lowest in freeze dried seed $(56.847 \%)$ after 2 months of storage. The shade dried fruits had relative advantage over sun-drying, freeze drying and oven drying were $18.484 \%, 30.149 \%$ and $2.363 \%$ respectively.
This trend was followed in the seed after 4 months of storage and 6 months of storage and the shade dried fruits had relative advantage over sun-drying, freeze drying and oven drying were $18.569 \%, 31.359 \%, 0.041 \%$ and $32.220 \%, 48.552 \%, 0.533 \%$ respectively. But after 8 and 10 months of storage, hand extracted seeds had highest germination percentage followed by shade dried seed the shade dried fruits had relative advantage over sun-drying, freeze drying and oven drying were $22.914 \%, \quad 74.524 \%,-14.523 \%$ and $24.456 \%, 139.792 \%,-8.980 \%$ respectively.

In the category of slender type of fruit, the highest germination was found in hand extracted seed $(73.478 \%)$ followed by shade dried seed $(72.156 \%)$ and lowest in freeze dried seed $(57.122 \%)$ after 2 months of storage. The shade dried fruits had relative advantage over sun-drying, freeze drying and oven drying were $16.631 \%, 26.319 \%$ and $1.899 \%$ respectively. This trend was followed in the seed after 4, 8 and 10 months of storage and the shade dried fruits had relative advantage over sun-drying, freeze drying and oven drying were $16.932 \%, 29.065 \%$, $1.210 \%$ (4 months after storage), $19.097 \%$, $73.732 \%,-14.579 \%$ (8 months after storage) and $10.583 \%, 134.085 \%,-9.359$ (10 months after storage). But after 6 months of storage, shade dried seeds had highest germination percentage $(65.211 \%)$ followed by hand extracted seed $(64.656 \%)$ and the shade dried fruits had relative advantage over sun-drying, freeze drying and oven drying were $29.472 \%$, $47.240 \%,-0.862 \%$ after 6 months of storage.

In most of the cases like shade dried seed, hand extracted seed, sun dried seed and oven dried seed showed more germination percentage in fleshy fruit type in compared to medium and slender type of fruit, but in freeze dried seed, the slender type of fruit showed maximum germination percentage followed by medium and fleshy fruit type (Fig. 1 and 2; Table 1-3). 
Table.1 Different fruit types in chilli genotypes based on fleshiness index

\begin{tabular}{|c|c|c|}
\hline Fruit Type & Landraces & \% of total samples \\
\hline Slender & $\begin{array}{c}\text { V7, V8, V9, V10, V11, V12, V14, V15, } \\
\text { V16, V17, V19, V20, V21,V23,V27 }\end{array}$ & $55.6 \%$ \\
\hline Medium & V2, V3, V4, V5, V18, V22 & $22.2 \%$ \\
\hline Fleshy & V1, V6, V13, V24, V25, V26 & $22.2 \%$ \\
\hline
\end{tabular}

Table.2 Seed germination percentage of chilli (Capsicum annuиm L.) dried under different conditions in ambient storage

\begin{tabular}{|l|c|c|c|}
\hline \multirow{2}{*}{ Drying methods \& Storage duration combination } & \multicolumn{3}{|c|}{ Germination \% Mean } \\
\cline { 2 - 4 } & Mlender & Medium & Fleshy \\
\hline M1D0 (Contol) & 77.056 & 78.083 & 82.444 \\
\hline M1D1 ( Shade Dried+ stored for 2 Months) & 73.478 & 75.556 & 79.139 \\
\hline M1D2 ( Shade Dried+ stored for 4 Months) & 67.989 & 69.000 & 71.028 \\
\hline M1D4 ( Shade Dried+ stored for 8 Months) & 65.211 & 65.486 & 66.181 \\
\hline M1D5 ( Shade Dried+ stored for 10 Months) & 49.611 & 48.722 & 48.917 \\
\hline M2D1 ( Hand Extracted + stored for 2 Months) & 32.278 & 31.806 & 32.333 \\
\hline M2D2 ( Hand Extracted + stored for 4 Months) & 72.156 & 73.986 & 77.292 \\
\hline M2D3 ( Hand Extracted + stored for 6 Months) & 68.178 & 68.972 & 69.694 \\
\hline M2D4 ( Hand Extracted + stored for 8 Months) & 64.656 & 64.667 & 65.222 \\
\hline M2D5 ( Hand Extracted + stored for 10 Months) & 32.767 & 33.889 & 55.250 \\
\hline M3D1 ( Sundried+ stored for 2 Months) & 61.867 & 62.444 & 33.250 \\
\hline M3D2 ( Sundried+ stored for 4 Months) & 58.144 & 58.194 & 58.139 \\
\hline M3D3 (Sundried+ stored for 6 Months) & 50.367 & 49.528 & 50.472 \\
\hline M3D4 ( Sundried+ stored for 8 Months) & 41.656 & 39.639 & 39.500 \\
\hline M3D5 (Sundried+ stored for 10 Months) & 29.189 & 25.556 & 24.250 \\
\hline M4D1 (Freeze Dried+ stored for 2 Months) & 57.122 & 56.847 & 56.569 \\
\hline M4D2 (Freeze Dried+ stored for 4 Months) & 52.678 & 52.528 & 52.278 \\
\hline M4D3 (Freeze Dried+ stored for 6Months) & 44.289 & 44.083 & 44.028 \\
\hline M4D4 (Freeze Dried + stored for 8Months) & 28.556 & 27.917 & 26.556 \\
\hline M4D5 (Freeze Dried + stored for 10Months) & 13.789 & 13.264 & 12.264 \\
\hline M5D1( Oven Dried + stored for 2Months) & 70.811 & 72.278 & 74.306 \\
\hline M5D2 ( Oven Dried + stored for 4Months) & 68.822 & 68.972 & 70.111 \\
\hline M5D3 ( Oven Dried + stored for 6 Months) & 65.778 & 65.139 & 66.167 \\
\hline M5D4 ( Oven Dried + stored for 8 Months) & 58.078 & 57.000 & 58.056 \\
\hline M5D5 ( Oven Dried + stored for 10Months) & 35.611 & 34.944 & 35.389 \\
\hline & 0.315 & 0.366 & 0.326 \\
\hline CD(m) & 0.896 & 1.041 & 0.928 \\
\hline & 1.190 & 1.382 & 1.233 \\
\hline & 1.02 & 1.19 & 1.04 \\
\hline
\end{tabular}




\begin{tabular}{|c|c|c|c|}
\hline \multicolumn{2}{|c|}{ Methods of Drying } & \multicolumn{2}{c|}{ Duration of Storage after drying } \\
\hline M1 : & Shade Dried & D1 : & 2 Months \\
\hline M2: & Hand Extracted & D2 : & 4 Months \\
\hline M3 : & Sundried & D3 : & 6 Months \\
\hline M4 : & Freeze Dried & D4 $:$ & 8 Months \\
\hline M5: & Oven Dried & D5 : & 10 Months \\
\hline
\end{tabular}

Table.3 Seed Vigour index of chilli (Capsicum annuum L.) dried under different conditions in ambient storage

\begin{tabular}{|l|c|c|c|}
\hline \multirow{2}{*}{ Drying methods \& Storage duration combination } & \multicolumn{3}{|c|}{ Vigour Index Mean } \\
\cline { 2 - 4 } & Slender & Medium & Fleshy \\
\hline M1D1 ( Shade Dried+ stored for 2 Months) & 922.169 & 1020.203 & 1099.250 \\
\hline M1D2 ( Shade Dried+ stored for 4 Months) & 842.787 & 810.631 & 943.553 \\
\hline M1D3 ( Shade Dried+ stored for 6 Months) & 718.669 & 878.325 & 856.436 \\
\hline M1D4 ( Shade Dried+ stored for 8 Months) & 662.957 & 727.190 & 851.451 \\
\hline M1D5 ( Shade Dried+ stored for 10 Months) & 381.657 & 449.839 & 558.292 \\
\hline M2D1 (Hand Extracted + stored for 2 Months) & 266.831 & 282.022 & 281.504 \\
\hline M2D2 ( Hand Extracted + stored for 4 Months) & 724.270 & 863.394 & 532.810 \\
\hline M2D3 ( Hand Extracted + stored for 6 Months) & 808.473 & 749.783 & 656.697 \\
\hline M2D4 ( Hand Extracted + stored for 8 Months) & 655.222 & 653.150 & 686.001 \\
\hline M2D5 (Hand Extracted + stored for 10 Months) & 475.247 & 499.408 & 581.600 \\
\hline M3D1 ( Sundried + stored for 2 Months) & 239.200 & 203.331 & 192.356 \\
\hline M3D2 ( Sundried + stored for 4 Months) & 556.887 & 636.475 & 578.763 \\
\hline M3D3 (Sundried + stored for 6 Months) & 517.317 & 531.406 & 489.619 \\
\hline M3D4 ( Sundried + stored for 8 Months) & 401.426 & 475.419 & 485.298 \\
\hline M3D5 (Sundried + stored for 10 Months) & 299.453 & 286.792 & 325.976 \\
\hline M4D1 (Freeze Dried + stored for 2 Months) & 156.088 & 143.472 & 137.182 \\
\hline M4D2 (Freeze Dried + stored for 4 Months) & 485.506 & 419.044 & 423.860 \\
\hline M4D3 (Freeze Dried + stored for 6Months) & 333.954 & 420.681 & 415.939 \\
\hline M4D4 (Freeze Dried + stored for 8Months) & 308.618 & 368.692 & 315.208 \\
\hline M4D5 (Freeze Dried + stored for 10Months) & 162.880 & 161.661 & 175.949 \\
\hline M5D1( Oven Dried + stored for 2Months) & 50.990 & 73.992 & 62.300 \\
\hline M5D2 ( Oven Dried + stored for 4Months) & 757.991 & 667.458 & 847.258 \\
\hline M5D3 ( Oven Dried + stored for 6 Months) & 751.821 & 733.725 & 797.347 \\
\hline M5D4 ( Oven Dried + stored for 8 Months) & 666.490 & 649.433 & 738.350 \\
\hline M5D5 ( Oven Dried + stored for 10Months) & 492.062 & 414.511 & 562.206 \\
\hline & 273.590 & 293.656 & 298.333 \\
\hline & 26.057 & 44.667 & 42.469 \\
\hline & 74.058 & 126.949 & 120.702 \\
\hline & 98.375 & 168.633 & 160.335 \\
\hline
\end{tabular}


Fig.1 Seed germination percentage of chilli (Capsicum annuиm L.) dried under different conditions and stored for different durations

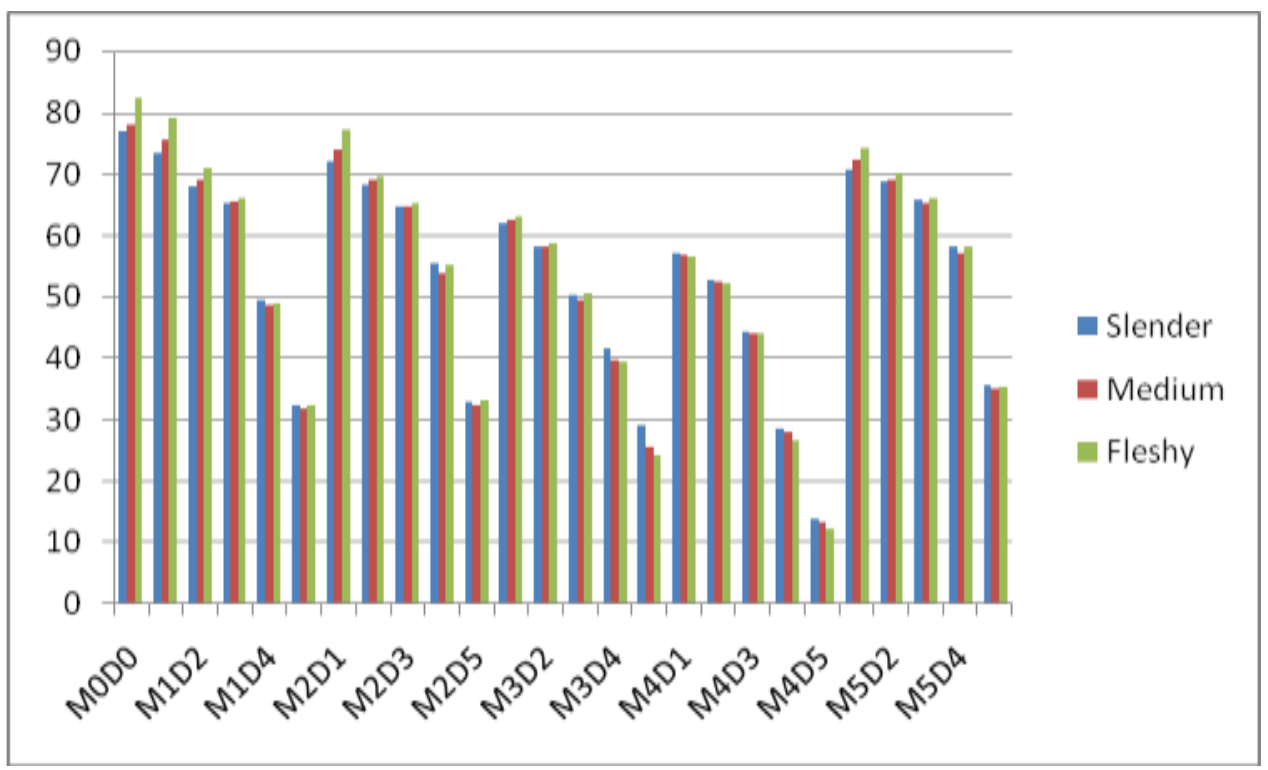

Fig.2 Vigour index of chilli (Capsicum annuum L.) dried under different conditions and stored for different durations

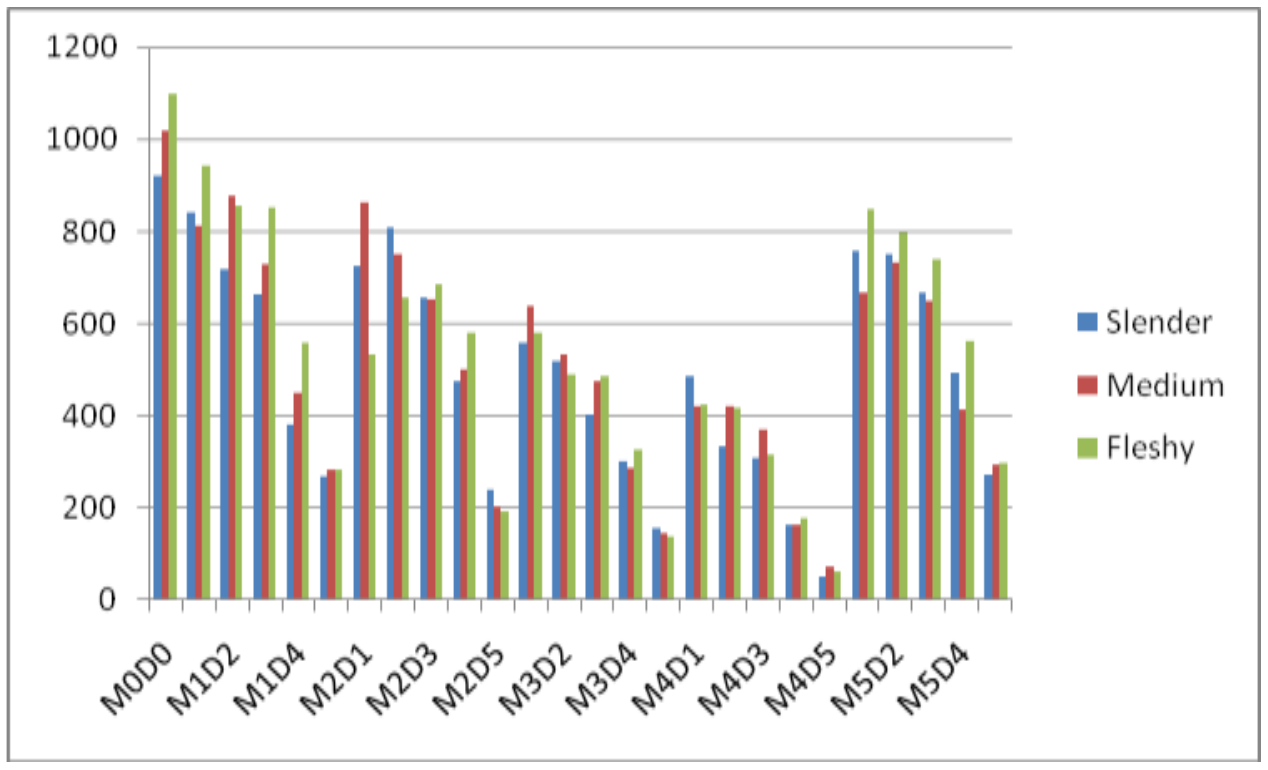

\section{Vigour index}

In the category of fleshy fruit type, shade dried seeds had highest vigour index (943.553) followed by oven dried seeds (847.258) and sundried seeds (578.763) and lowest in freeze dried seeds (423.860) after 2 months of storage. This same trend was observed in seeds after 4 and 6 months after storage. But after 8 months of storage, highest vigour index observed in hand extracted seed (581.600) followed by oven dried seed (562.206) and shade dried seed (558.292) and after 10 months of storage highest vigour 
index found in oven dried seed (298.333) followed by shade dried seed (281.504). In the category of medium fleshy fruit type, hand extracted seeds had highest vigour index (863.394) followed by shade dried seeds (810.631) and oven dried seeds (667.458) and lowest in freeze dried seeds (419.044) after 2 months of storage and this same trend was observed in seeds after 8 months of storage.

But after 4 and 6 months of storage highest vigour index observed in shade dried seed (878.325 and 727.190 respectively) followed by hand extracted seed (749.783 and 653.150 respectively) and after 10 months of storage highest vigour index found in oven dried seed (293.656) followed by shade dried seed (282.022). In the category of slender fruit type, shade dried seeds had highest vigour index (842.787) followed by oven dried seeds (757.991) and hand extracted seeds (724.270) and lowest in freeze dried seeds (485.506) after 2 months of storage and this same trend was observed in seeds after 4 months of storage.

Drying methods and fleshiness index played very important role in seed quality in the present experiment. Results can be better interpreted by understanding the fact that, chilli seed attains physiological and functional maturity at high seed moisture content of 39$40 \%$ and the rate of moisture migration from center to surface of the seed is influenced by temperature, pericarp thickness, chemical composition of seed and seed coat permeability. The rate of moisture removal from the surface of seed is influenced by degree of surface saturation, thickness of the pericarp or fleshiness of the fruit, relative humidity and temperature of drying air. If evaporation from the seed surface occurs too rapidly it can damage the embryo, therefore seed should be dried carefully to arrest stress damage due to heat. In contrast, if moisture elimination takes place too slowly it may favour invasion of pathogens (Harrington, 1972). In the present experiment shade drying of chilli fruits harvested at red maturity or physiological maturity was found to be the most effective method of drying in all the three types of fruit i.e. slender, medium and fleshy. Seeds extracted and shade dried on the day of harvest was also effective for a certain period in all fruit types (Patraet al., 2016). Sun drying was less effective for seed purpose. Similar results were reported by Thiagarajan (1983) in chillies.

These results are in agreement with the findings of Dhanelappagol et al., (1988) in chillies, Javaregowda et al., (1990) in tomato and Shivahre et al., (1995) in chillies. Heat tolerance of seed varies with the species. For drying of vegetable seed, temperature not exceeding $350 \mathrm{C}$ has been advocated by Harrington (1972).This variation in seed quality parameters among different fruit types may be due to existence of variability and storability for different duration of storage.

Drying requirements of chilli seed was found to be very peculiar and depends on thickness of the pericarp or fleshiness index, type of fruits in a view to get good quality of chilli seeds along with it plays an important role in storability of chilli seeds. The present experiment evaluated all these aspects and revealed that shade drying of chilli fruits harvested at physiological maturity or seeds extracted on the same day of harvest followed by shade drying are useful for maintaining seed viability and vigour up to 6 months duration of safe storage. After that, its quality got drastically reduced in all fruit types of chilli such as slender, medium and fleshy.

\section{References}

Abdul Baki, A.A., Anderson J.D., 1973, Vigor determination in soybean by multiple criteria. Crop Sci., 13: 630-633.

Barua H., Rahman M.M., Masud M.M. 2009, 
Effect of storage containers environment at different storage period on the quality of chilli seed. International Journal on Sustain Crop Production 4(4):28-32.

Bellad S., 1997, Effect of exhaustion and drying methods on quality of potato seed (Solanum tuberosum L.) M.Sc. (Agril) thesis, University of Agricultural Sciences, Dharwad.

Cavero J., Ortega R.G., 1995, Influence of fruit ripeness at the time of seed extraction on pepper (Capsicum annuum L.) seed germination. Scientia Horticulture, 60(34):345-352

Christensen C.M., Kaufman C.M., 1965, Deterioration of stored grains by fungi. Annual Review of Phytopathology, 3:69-84.

Copeland L.O., 1976, Principles of Seed Science and Technology, Burgess Publication Co., Minnessot.

Dhanelappagol, M. S., Shashidhara, S. D., Kulkarni, G.N., 1988, Studies on drying characteristics of chillies. Journal of Agricultural Engineering, 25: 72-75.

Harrington J.F. 1972, Seed storage and longevity. In Seed Biology, 3: 145-245.

Javaregowda S., Talukdar K.C., Ramaih H., 1990, Effect of drying methods on seed quality in tomato. Seed Research, 18: 126-1629.

Nagaraja A., Basavaraja P.K., Yogeesha H.S., 1998, Effect of drying methods on fruit and seed quality of chilli. South Indian Horticulture, 46(3/6): 262-265

Patil K.N., Nagaraja A., 1999, Effect of storage methods on quality of chilli seeds.
Karnataka Journal of Agricultural Sciences, 12(1/4): 74-80

Patra C., Sahoo L.P., Sasamala A.C. and Mohanty S.K. 2016. Studying the effect of different fruit and seed drying methods on seed quality of two different genotypes of chilli (Capsicum annuum L.). International Journal of Science, Environment and Technology, 5(5): 3262-3270

RadheShyam, Arora S.K., Tomer R.P.S., 1996, Effect of seed extraction interval on seed quality of chilli (Capsicum annuum L.) cultivars. Haryana Agricultural University Journal of Research, 26(3): 183-186

Sahoo L.P., 2014, fruit and seed development pattern and seed storability of some genotypes of chilli (Capsicum annuum L.). Ph.D. thesis, Department of Seed Science and Technology, Orissa University of Agriculture \& Technology, Bhubaneswar, Odisha, India.

Shivahre V.S., Singh B.P., Saxena RP, 1995, Drying characteristic of chillies. Phala Samskarana, 19: 401-407

Thiagarajan, L. P., 1983, Studies on certain aspects of production, processing and storage of chilli (Capsicum annuum L.) seed. Ph.D. thesis, Tamil Nadu Agricultural University, Coimbatore.

Vinod Kumar, 1998, Effect of stage of harvesting and drying methods on seed quality of paprika chilli (Capsicum annuum L.), M. Sc. (Agril.) thesis, University of Agricultural Sciences, Dharwad.

\section{How to cite this article:}

Chakradhar Patra, Laxmipriya Sahoo, Saroj Kumar Mohanty and Monalisha Sahoo. 2019. Standardization of Drying Methods of different Fruit Types on Storability of Chilli Seed. Int.J.Curr.Microbiol.App.Sci. 8(10): 772-780. doi: https://doi.org/10.20546/ijcmas.2019.810.089 